\title{
THE pH-DEPENDENT INFLUENCE OF AMINOGLYCOSIDE ANTIBIOTICS ON IODOHIPPURATE ACCUMULATION IN RABBIT RENAL CORTICAL SLICES
}

\author{
Nils Milman and Jørgen Dahlager \\ Division of Nephrology, Department of Medicine P and Division of Urology, \\ Department of Surgery D, Rigshospitalet (Copenhagen University Hospital), \\ Copenhagen, Denmark \\ (Received for publication July 7, 1978)
}

\begin{abstract}
The effects of aminoglycoside antibiotics on ${ }^{125} \mathrm{I}$-hippurate $(\mathrm{OIH})$ accumulation in rabbit renal cortical slices were assessed in vitro using incubation media with $\mathrm{pH}$-values ranging from 6.4 to 8.4 and containing streptomycin, kanamycin, amikacin, gentamicin and tobramycin in concentrations ranging from 100 to $2,000 \mu \mathrm{g}$ base $/ \mathrm{ml}$. The aminoglycoside-induced inhibition of $\mathrm{OIH}$ accumulation was clearly $\mathrm{pH}$-dependent and most pronounced at alkaline $\mathrm{pH}$-values. At pH 6.4 and 7.4 the aminoglycosides had either no or only moderate effects on OIH accumulation, while all drugs produced a distinct depression in accumulation at $\mathrm{pH} 7.9$ and 8.4. The microbiologically inert $N$-acetyl gentamicin had no influence on accumulation. The influence of aminoglycosides on $\mathrm{OIH}$ accumulation is probably related to the $\mathrm{pKa}$-values of these drugs and implies the presence of free amino groups.
\end{abstract}

In a previous study it was demonstrated that aminoglycoside antibiotics in vitro depressed the accumulation of ${ }^{125}$ I-hippurate $(\mathrm{OIH})$ in rabbit renal cortical slices ${ }^{11}$. However, the measured effects were partially explained by aminoglycoside-induced $\mathrm{pH}$-changes in the incubation media. Therefore, in the present investigation the influence of aminoglycosides on $\mathrm{OIH}$ accumulation has been studied under well-defined $\mathrm{pH}$ conditions.

\section{Materials and Methods}

Measurement of ${ }^{125}$ I-hippurate accumulation

The technique employed is a modification of the method reported by CROSS and TAGGART ${ }^{2)}$ and has been described in details previously ${ }^{1 \prime}$. Rabbit renal cortical slices were incubated in Erlenmeyer vessels for 60 minutes at $25^{\circ} \mathrm{C}$ with $100 \%$ oxygen in the gas space, while being shaken at 100 cycles/minute. Each vessel contained $90 \sim 110 \mathrm{mg}$ slices, $10 \mathrm{ml}$ Cross-TAGGART medium ${ }^{2)}$ and $20 \mu \mathrm{Ci} o-{ }^{125}$ I-hippurate/ liter, corresponding to approximately $3 \mu \mathrm{mol} / \mathrm{liter}$. The slices and aliquots of the incubation media were counted in a gamma scintillation counter, and the $\mathrm{OIH}$ accumulation expressed as the slice to medium ratio, i.e. the ratio of the counts in $1 \mathrm{~g}$ tissue to those in $1 \mathrm{ml}$ incubation medium.

Aminoglycoside studies

Prior to incubation the following aminoglycosides were added to the incubation media in concentrations ranging from 100 to $2,000 \mu \mathrm{g}$ base $/ \mathrm{ml}$ : Streptomycin sulfate (714 $\mu \mathrm{g}$ base $/ \mathrm{mg}$ ), kanamycin sulfate (777 $\mu \mathrm{g}$ base/mg), amikacin base ( $895 \mu \mathrm{g}$ base $/ \mathrm{mg}$ ), gentamicin sulfate (571 $\mu \mathrm{g}$ base $/ \mathrm{mg}$ ), tobramycin base $\left(925 \mu \mathrm{g}\right.$ base $/ \mathrm{mg}$ ) and microbiologically inert $N$-acetyl gentamicin ${ }^{3)}$ (690 $\mu$ g calculated base/ $\mathrm{mg}$ ) as a control substance. After addition of aminoglycosides $\mathrm{pH}$ was adjusted to values ranging from 6.4 to 8.4 with $5 \mathrm{~N} \mathrm{HCl}$ or $5 \mathrm{~N} \mathrm{NaOH}$ and using a pH-meter. Incubations were then performed as described above. Each experiment included 4 control vessels with identical $\mathrm{pH}$ and without aminoglycoside. The $\mathrm{OIH}$ accumulation in the aminoglycoside-containing vessels was expressed in per cent of the accumulation in the control vessels. 
STUDENT's $t$-tests for paired and unpaired values were employed in statistical evaluation of the results.

\section{Results}

The effects of aminoglycosides on $\mathrm{OIH}$ accumulation are summarized in Tables $1 \sim 3$ and Figs. $1 \sim 3$. The results represent the averages of $4 \sim 8$ experiments. According to the accumulation profiles (dose response curves) the aminoglycosides could be divided in three groups. I. Streptomycin. II. Kanamycin and amikacin. III. Gentamicin and tobramycin.

\section{Streptomycin}

Accumulation was significantly depressed by concentrations $\geq 500 \mu \mathrm{g} / \mathrm{ml}$ at $\mathrm{pH} 6.4$ (Table 1 and Fig. 1), but unaffected even by high concentrations at $\mathrm{pH} 6.9$ and 7.4, whereas a profound drop was observed at $\mathrm{pH} 7.9$ and 8.4 .

Table 1. Effects of streptomycin and $N$-acetyl gentamicin on ${ }^{125}$ I-hippurate accumulation in rabbit renal cortical slices at different $\mathrm{pH}$-values in the incubation media.

Results are expressed in per cent of the accumulation in aminoglycoside-free controls (mean \pm S.D.).

\begin{tabular}{l|r|r|r|r|r|r}
\hline & \multirow{2}{*}{} & \multicolumn{5}{|c}{${ }^{125}$ I-Hippurate accumulation } \\
\cline { 3 - 7 } & & $\mathrm{pH} \mathrm{6.4}$ & $\mathrm{pH} 6.9$ & $\mathrm{pH} 7.4$ & $\mathrm{pH} 7.9$ & $\mathrm{pH} 8.4$ \\
\hline & 100 & $86.9 \pm 6.2$ & $104.4 \pm 4.4$ & $95.4 \pm 5.6$ & $65.8 \pm 2.3^{*}$ & $72.2 \pm 24.6^{*}$ \\
\multirow{3}{*}{$\begin{array}{l}\text { Streptomycin base } \\
(\mu \mathrm{g} / \mathrm{ml})\end{array}$} & 500 & $79.4 \pm 8.6^{*}$ & $101.9 \pm 3.7$ & $92.6 \pm 6.8$ & $45.9 \pm 8.6^{*}$ & $50.4 \pm 15.8^{*}$ \\
& 1,000 & $85.1 \pm 11.7^{*}$ & $96.7 \pm 2.5$ & $86.2 \pm 8.3$ & $18.4 \pm 1.4^{*}$ & $12.0 \pm 9.8^{*}$ \\
& 2,000 & $72.2 \pm 11.5^{*}$ & $97.1 \pm 2.0$ & $93.1 \pm 8.0$ & $13.8 \pm 8.5^{*}$ & $9.1 \pm 7.1^{*}$ \\
\hline & 100 & $104.4 \pm 11.0$ & $111.4 \pm 7.8$ & $103.9 \pm 6.7$ & $97.9 \pm 5.8$ & $98.7 \pm 16.5$ \\
$N$-Acetyl gentamicin & 500 & $100.0 \pm 9.6$ & $99.0 \pm 11.4$ & $90.6 \pm 8.5$ & $97.3 \pm 7.4$ & $110.3 \pm 13.2$ \\
base $(\mu \mathrm{g} / \mathrm{ml})$ & 1,000 & $88.2 \pm 6.3$ & $94.9 \pm 9.2$ & $98.8 \pm 11.6$ & $101.9 \pm 14.3$ & $92.6 \pm 14.3$ \\
& 2,000 & $72.9 \pm 6.0 *$ & $84.4 \pm 16.7$ & $98.1 \pm 5.8$ & $86.0 \pm 8.9$ & $104.3 \pm 19.0$ \\
\hline
\end{tabular}

* $\mathrm{P}<0.05$

Fig. 1. Effects of streptomycin and $N$-acetyl gentamicin on ${ }^{125}$ I-hippurate accumulation in rabbit renal cortical slices.

Accumulation is expressed in per cent of values in aminoglycoside-free controls.

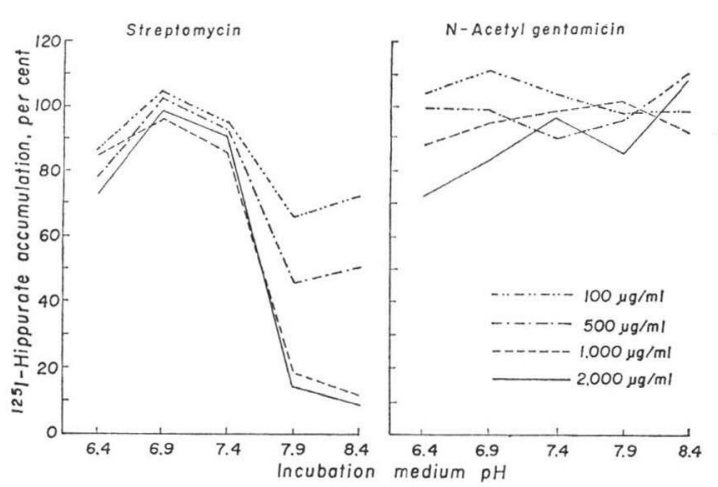

Fig. 2. Effects of kanamycin and amikacin on ${ }^{125}$ I-hippurate accumulation in rabbit renal cortical slices.

Accumulation is expressed in per cent of values in aminoglycoside-free controls.

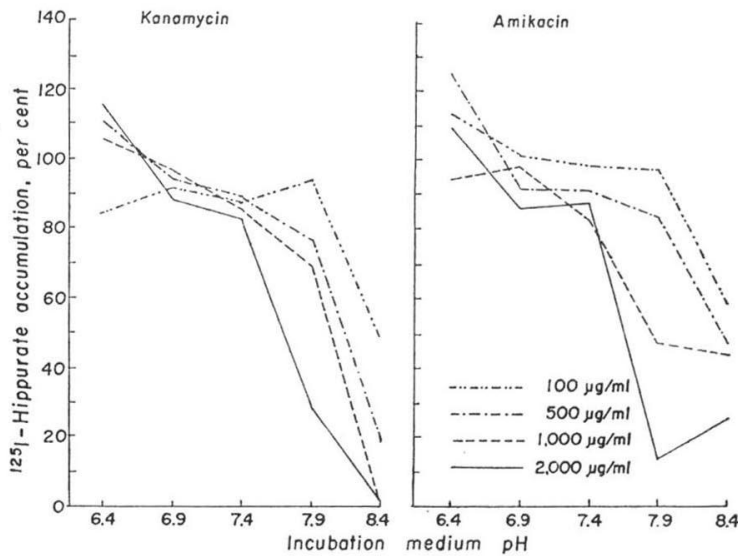


Table 2. Effects of kanamycin and amikacin on ${ }^{125} \mathrm{I}$-hippurate accumulation in rabbit renal cortical slices at different $\mathrm{pH}$-values in the incubation media.

Results are expressed in per cent of the accumulation in aminoglycoside-free controls (mean \pm S.D.).

\begin{tabular}{|c|c|c|c|c|c|c|}
\hline & & \multicolumn{5}{|c|}{${ }^{125} \mathrm{I}$-Hippurate accumulation } \\
\hline & & $\mathrm{pH} 6.4$ & pH 6.9 & pH 7.4 & pH 7.9 & pH 8.4 \\
\hline \multirow{4}{*}{$\begin{array}{l}\text { Kanamycin base } \\
(\mu \mathrm{g} / \mathrm{ml})\end{array}$} & 100 & $84.0 \pm 8.2$ & $92.1 \pm 10.6$ & $88.3 \pm 8.2$ & $94.0 \pm 9.0$ & $48.9 \pm 13.2^{*}$ \\
\hline & 500 & $113.6 \pm 6.0$ & $94.2 \pm 3.2$ & $88.6 \pm 21.6$ & $76.3 \pm 7.8^{*}$ & $18.4 \pm 15.0^{*}$ \\
\hline & 1,000 & $105.3 \pm 43.2$ & $95.8 \pm 13.6$ & $85.4 \pm 10.2$ & $69.5 \pm 13.2 *$ & $0.6 \pm 0.8^{*}$ \\
\hline & 2,000 & $115.1 \pm 25.6$ & $88.2 \pm 14.6$ & $82.6 \pm 4.8$ & $28.3 \pm 13.2 *$ & $0.0 *$ \\
\hline \multirow{4}{*}{$\begin{array}{l}\text { Amikacin base } \\
(\mu \mathrm{g} / \mathrm{ml})\end{array}$} & 100 & $113.6 \pm 17.6$ & $101.0 \pm 14.0$ & $98.5 \pm 3.6$ & $97.4 \pm 15.8$ & $58.4 \pm 11.9^{*}$ \\
\hline & 500 & $125.3 \pm 23.2$ & $91.5 \pm 15.6$ & $90.1 \pm 7.0$ & $84.2 \pm 23.4$ & $46.7 \pm 10.0^{*}$ \\
\hline & 1,000 & $94.8 \pm 11.8$ & $102.3 \pm 6.0$ & $81.9 \pm 5.0$ & $47.5 \pm 21.2 *$ & $44.4 \pm 7.0 *$ \\
\hline & 2,000 & $108.6 \pm 20.4$ & $85.2 \pm 5.2$ & $87.4 \pm 13.7$ & $14.4 \pm 9.2 *$ & $26.1 \pm 26.0^{*}$ \\
\hline
\end{tabular}

* $\quad \mathbf{P}<0.05$

Table 3. Effects of gentamicin and tobramycin on ${ }^{125}$ I-hippurate accumulation in rabbit renal cortical slices at different $\mathrm{pH}$-values in the incubation media.

Results are expressed in per cent of the accumulation in aminoglycoside-free controls (mean \pm S.D.).

\begin{tabular}{|c|c|c|c|c|c|c|}
\hline & & \multicolumn{5}{|c|}{${ }^{125} \mathrm{I}$-Hippurate accumulation } \\
\hline & & $\mathrm{pH} 6.4$ & pH 6.9 & $\mathrm{pH} 7.4$ & pH 7.9 & $\mathrm{pH} 8.4$ \\
\hline \multirow{4}{*}{$\begin{array}{l}\text { Gentamicin base } \\
(\mu \mathrm{g} / \mathrm{ml})\end{array}$} & 100 & $88.5 \pm 9.2$ & $69.3 \pm 5.5^{*}$ & $115.1 \pm 12.0$ & $102.3 \pm 20.3$ & $68.3 \pm 7.8^{*}$ \\
\hline & 500 & $78.3 \pm 10.4$ & $71.5 \pm 7.0^{*}$ & $113.5 \pm 10.7$ & $84.2 \pm 4.2$ & $22.6 \pm 6.6^{*}$ \\
\hline & 1,000 & $64.1 \pm 13.9 *$ & $67.6 \pm 3.5^{*}$ & $102.3 \pm 13.4$ & $64.1 \pm 11.0 *$ & $4.9 \pm 2.3^{*}$ \\
\hline & 2,000 & $60.7 \pm 10.0^{*}$ & $64.2 \pm 8.3^{*}$ & $119.3 \pm 3.5$ & $44.9 \pm 1.8 *$ & $1.3 \pm 1.7^{*}$ \\
\hline \multirow{4}{*}{$\begin{array}{l}\text { Tobramycin base } \\
(\mu \mathrm{g} / \mathrm{ml})\end{array}$} & 100 & $94.3 \pm 7.8$ & $81.7 \pm 10.9 *$ & $90.7 \pm 4.0$ & $77.7 \pm 3.8^{*}$ & $55.6 \pm 7.2^{*}$ \\
\hline & 500 & $93.3 \pm 6.9$ & $81.7 \pm 12.6^{*}$ & $103.7 \pm 6.4$ & $33.0 \pm 16.8^{*}$ & $6.0 \pm 6.6^{*}$ \\
\hline & 1,000 & $88.0 \pm 8.6$ & $83.7 \pm 6.2 *$ & $98.0 \pm 1.7$ & $26.2 \pm 9.2 *$ & $2.5 \pm 3.0^{*}$ \\
\hline & 2,000 & $75.3 \pm 30.7$ & $73.0 \pm 7.5^{*}$ & $94.0 \pm 0.7$ & $5.0 \pm 1.7 *$ & $0.0 *$ \\
\hline
\end{tabular}

* $\quad \mathrm{P}<0.05$

Kanamycin and Amikacin

Had no significant influence on accumulation at pH 6.4, 6.9 and 7.4 (Table 2 and Fig. 2), but produced a distinct decrease at $\mathrm{pH} 7.9$ and 8.4. There were no significant differences between the accumulation profiles of the two drugs, except at pH 8.4 where kanamycin depressed accumulation more than amikacin in concentrations $\geq 500 \mu \mathrm{g} / \mathrm{ml}$.

Gentamicin and Tobramycin

At $\mathrm{pH} 6.4$ gentamicin produced a significant decrease in accumulation in concentrations $\geq$ $1,000 \mu \mathrm{g} / \mathrm{ml}$, while the influence of tobramycin was insignificant (Table 3 and Fig. 3). At pH 6.9 both drugs produced a significant decrease in
Fig. 3. Effects of gentamicin and tobramycin on ${ }^{125}$ I-hippurate accumulation in rabbit renal cortical slices.

Accumulation is expressed in per cent of values in aminoglycoside-free controls.

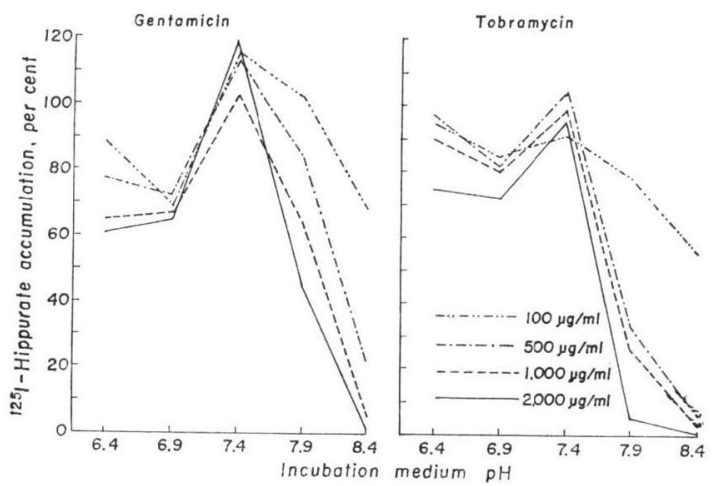


accumulation already from $100 \mu \mathrm{g} / \mathrm{ml}$, which was relatively independent of the aminoglycoside concentration. Accumulation was unaffected at $\mathrm{pH} 7.4$, and distinctly reduced at $\mathrm{pH} 7.9$ and 8.4. Gentamicin had significantly higher accumulation profiles than tobramycin at $\mathrm{pH} 7.9$ and 8.4.

\section{$N$-Acetyl gentamicin}

Produced a significant decrease in accumulation only in the highest concentration at $\mathrm{pH} 6.4$, while accumulation was unaffected at all other $\mathrm{pH}$-values (Table 1 and Fig. 1). $\mathrm{N}$-Acetyl gentamicin had significantly higher accumulation profiles than gentamicin at $\mathrm{pH} 6.4,6.9,7.9$ and 8.4, but not at $\mathrm{pH} 7.4$.

Common features for the microbiologically active aminoglycosides were the absent effects on accumulation at pH 7.4, and the pronounced decrease observed at more alkaline pH-values. Accordingly there were no significant differences between the accumulation profiles of the various aminoglycosides at $\mathrm{pH}$ 7.4. When arranged according to their influence on $\mathrm{OIH}$ accumulation at $\mathrm{pH} 7.9$ the order became: Gentamicin $<$ kanamycin $=$ amikacin $<$ streptomycin $=$ tobramycin. At $\mathrm{pH} 8.4$ the order was: Amikacin $<$ streptomycin $<$ gentamicin $<$ tobramycin $=$ kanamycin.

\section{Discussion}

The accumulation of $\mathrm{OIH}$ in renal cortical slices is distinctly affected by the presence of aminoglycosides. Other authors have also demonstrated an in vitro inhibitory effect of gentamicin on $p$ aminohippurate accumulation in rat cortical slices ${ }^{4,5)}$, but have not mentioned that this partially could be explained through aminoglycoside-induced $\mathrm{pH}$-changes in the incubation media.

The accumulation profiles varied with the type of aminoglycoside employed in the experiment and were identical for drugs with related chemical structure. Differences in accumulation profiles were most pronounced in the acid area, where streptomycin, gentamicin and tobramycin depressed accumulation slightly, while this was unaffected by kanamycin and amikacin. All drugs had no influence at $\mathrm{pH} 7.4$ and produced a distinct decrease in the alkaline area. Kanamycin and amikacin displayed "simple" accumulation profiles, showing a gradual decrease in accumulation contemporary with an increase in $\mathrm{pH}$, whereas streptomycin, gentamicin and tobramycin had "complex" accumulation profiles in the acid area. These features impede a simple interpretation of the results as regards the lastmentioned three drugs and suggest that different mechanisms are responsible for the effects on accumulation in the acid and alkaline area, respectively.

The mechanism of the aminoglycoside-induced inhibition of $\mathrm{OIH}$ accumulation is unclarified, but the effect is probably exerted on a toxic-metabolic intracellular level. These drugs are accumulated in high concentrations in proximal tubular cells and compromise among other things mitochondrial function $^{61}$.

According to the theory of nonionic diffusion uncharged molecules penetrate more easily through biological membranes than charged molecules ${ }^{7}$. An increase in $\mathrm{pH}$ of the incubation medium reduces the charges of the basic aminoglycoside molecules and facilitates entrance into tubular cells. The low intracellular $\mathrm{pH}$ favours retention by protonation and contribute to the high intracellular concentration $^{81}$. The measured decrease in $\mathrm{OIH}$ accumulation at alkaline $\mathrm{pH}$-values is therefore probably partially explained by enhanced intracellular penetration due to diminished ionization. As a parallel it is known that the antimicrobial effect of aminoglycosides is $\mathrm{pH}$-dependent and greatest at alkaline $\mathrm{pH}$-values $^{9)}$, possibly due to better penetration into bacteria. The pKa-values of the individual amino groups determine the total charge of the aminoglycoside molecule at any given $\mathrm{pH}$. A high pKa should therefore be related to poor intracellular penetration and to a smaller effect on OIH accumulation. However, there was no clear connection between the average pKa-value of the individual aminoglycoside and its influence on accumulation, indicating that other differences in chemical structure are of importance for the effect on tubular cells.

$\mathrm{N}$-Acetyl gentamicin in which the amino groups have been blocked by acetylation is microbiologically inert and non-toxic ${ }^{31}$ and had no influence on $\mathrm{OIH}$ accumulation. Consequently the presence of free 
amino groups is essential for the depressive effect on accumulation.

All the studied aminoglycoside antibiotics possess nephrotoxic properties. Streptomycin, on a weight basis, is the least toxic, kanamycin and amikacin occupy an intermediate position, while gentamicin and tobramycin display the greatest degree of nephrotoxicity ${ }^{10,11,12)}$. There existed no correlation between the in vivo recognized renal toxicity of these drugs and the measured in vitro influence on $\mathrm{OIH}$ accumulation at neutral and alkaline $\mathrm{pH}$-values. However, at $\mathrm{pH} 6.9$ gentamicin and tobramycin had significantly greater effects on accumulation than the other aminoglycosides and as a parallel it has been reported that gentamicin nephrotoxicity is potentiated by metabolic acidosis in rats $^{13}$. However, systematic studies of the influence of changes in acid-base balance on aminoglycoside nephrotoxicity have not been performed.

Alkalisation of the urine is recommended in aminoglycoside treatment of urinary infections, in order to achieve maximum antimicrobial effect ${ }^{10,14)}$. However, the presented results suggest that alkalosis potentiate the nephrotoxicity of these drugs. Furthermore monosaccharides of the D-glucarate species protect against aminoglycoside-induced renal damage, possibly through a decrease in urinary $\mathrm{pH}^{15)}$. Therefore the indication for urinary alkalisation should be carefully reconsidered.

\section{Acknowledgements}

The authors are indebted to Dr. MARVIN J. WeInSTEIN, Schering Corp., U.S.A. for providing gentamicin and $\mathrm{N}$-acetyl gentamicin; Eli Lilly \& Co., U.S.A. for providing tobramycin; Bristol-Myers Co., U.S.A. for providing kanamycin and amikacin, and to Novo Ltd., Denmark for providing streptomycin.

\section{References}

1) Dahlager, J. \& N. Milman: Aminoglycoside nephrotoxicity. I. Effects of aminoglycoside antibiotics on iodohippurate accumulation in rabbit renal cortical slices. J. Antibiotics 30: 597 603, 1977

2) Cross, R. J. \& J. V. Taggart: Renal tubular transport: Accumulation of $p$-aminohippurate by rabbit kidney slices. Am. J. Physiol. 161: 181 190, 1950

3) Weinstein, M. J.; G. H. Wagman \& R. I. Taber: Toxicity of acetylated gentamicin and neomycin. Antimicr. Agents \& Chemoth.- 1965: 227 231, 1966

4) Cohen, L.; R. Lapkin \& G. J. Kaloyanides: Effect of gentamicin on PAH uptake by rat kidney slices. J. Pharmacol. Exp. Ther. 193: 264 270, 1975

5) Hirsch, G. H.; A. J. BAyne \& A. P. PAKuts: Gentamicin: Nephrotoxicity and effects on renal organic ion transport. Fed. Proc. 34: 803, 1975

6) Fillastre, J. P.; J. P. Morin, J. P. Bendirdjian \& M. Godin: Accumulation rénale des aminosides. Proc. 7th Int. Congress Nephrol., pp. 289 297, Montreal, 1978

7) Mudge, G. H.; P. Silva \& G. R. Stibitz: Renal excretion by non-ionic diffusion. Med. Clin. North Am. 59: $681 \sim 698,1975$

8) De Duve, C.; T. De Barsy, B. Poole, A. Trouet, P. Tulkens \& F. Van Hoof: Lysosomotropic agents. Biochem. Pharmac. 23: 2495 2531, 1974

9) Rubenis, M.; V. M. KozIJ \& G. G. Jackson: Laboratory studies on gentamicin. Antimicr. Agents \& Chemoth.-1962: $153 \sim 156,1963$

10) Weinstein, L.: Antimicrobial agents. Streptomycin, gentamicin and other aminoglycosides. In L. S. Goodman \& A. Gilman (ed.), The pharmacological basis of therapeutics, fifth edition, pp. $1167 \sim 1182$. MacMillan Publishing Co., New York, 1975

11) Kovnat, P.; E. Labovitz \& S. P. Levison: Antibiotics and the kidney. Med. Clin. North Am. 57: 1045 1063, 1973

12) Milman, N.: Renal failure associated with gentamicin therapy. Acta Med. Scand. 196: 87 91, 1974

13) Hsu, C. H.; T. W. Kurtz, R. E. Easterling \& J. M. Weller: Potentiation of gentamicin nephrotoxicity by metabolic acidosis. Proc. Soc. Exp. Biol. Med. 146: 894 897, 1974

14) Stamey, T. A.: Urinary tract infections. In G. G. Jackson, E. Escargaza, L. P. Garrod, H. Neu \& Y. UEDA (ed.), Gentamicin: Review and commentary on selected world literature, pp. 129 141. Schering Corp., Kenilworth, New Jersey, U.S.A., 1974

15) Furuno, K.; K. Ando, S. Suzuki \& K. Hirata: Effect of D-glucarates on basic antibiotic-induced renal damage in rats. J. Antibiotics 29: $187 \sim 194,1976$ 